\title{
EDITORIAL
}

\section{Why are bleeding trauma patients still dying?}

\author{
Karim Brohi ${ }^{1,2,3^{*}} \mathbb{E}$, Russell L. Gruen ${ }^{4,5}$ and John B. Holcomb ${ }^{6}$
}

(c) 2019 Springer-Verlag GmbH Germany, part of Springer Nature

Haemorrhage after injury contributes to over half of the five million traumatic deaths that occur every year. Since acute traumatic coagulopathy was described 15 years ago, trauma resuscitation has transformed. Now, rapid control of bleeding and maintenance of the blood's haemostatic competence are prioritized-a paradigm known as 'damage control' or 'haemostatic' resuscitation-with dramatic reductions in pre-hospital and in-hospital mortality [1-3]. Yet for the most critically injured patients requiring emergent surgery, overall mortality has changed little, and remains close to $50 \%[4,5]$. Despite improved haemorrhage control, many patients still die, and often not from exsanguination but later in their clinical course, through mechanisms which are not yet fully understood (Fig. 1).

Although most haemorrhagic deaths still occur prehospital, numbers have been reduced through the institution of regional trauma systems and the introduction of damage control interventions such as extremity tourniquets, pelvic binders, balloon occlusion of the aorta, tranexamic acid, plasma and whole blood. More patients are now surviving to reach hospital; and they are overall more severely injured, have had more profound shock, and have sustained more distal ischaemia from pre-hospital interventions.

Even 10 years ago early in-hospital haemorrhagic death due to profound coagulopathy was common, with patients oozing blood the consistency of cranberry juice from their wounds, mucosae and needle puncture sites. Today damage control resuscitation is continued during urgent surgery with haemostatic blood products, often guided by modern point of care coagulation analysers,

\footnotetext{
*Correspondence: k.brohi@qmul.ac.uk

${ }^{1}$ Queen Mary University of London, London, UK

Full author information is available at the end of the article
}

and exsanguination from coagulopathy on the operating table is rare. The early intraoperative deaths that do occur are most commonly from cardiac arrest due to severe hyperkalaemia, hypocalcaemia and acidaemia.

Operative survivors now arrive in critical care in a much better physiological condition, often with normalised perfusion and normalised coagulation at the end of their procedure. Their injuries have been fixed surgically, and their incision sites closed. But, some hours or days later, up to $25 \%$ of them will still die $[3,6]$. Over half of all in-hospital haemorrhage-associated deaths now occur after the first $24 \mathrm{~h}$. Some patients will die due to a concomitant primary brain injury. Other modes of death in these patients have not been well characterised. Historically later deaths have stemmed from multiple organ failure, but acute respiratory distress syndrome and renal failure are now usually moderate in severity, self-limiting, and managed routinely with organ support. Abdominal compartment syndrome has all but disappeared. The contemporary trauma patient rarely dies of the condition most clinicians have in mind when they think of multiple organ failure [7].

There appear to be two main organ dysfunction mechanisms through which trauma patients now succumb. First there is a group of early deaths that occur within the first hours or days after injury and seem determined by a profound cardiac and vascular failure. A typical sequence of events is that a patient leaves the operating room on minimal vasopressor support, initially with an appropriately high cardiac output. However, within a few hours a complex picture of cardiogenic, hypovolaemic and distributive shock develops. Vasopressor dose begins to increase, and over the next $48 \mathrm{~h}$ a second agent is added, and perhaps a third. Meanwhile, vascular volume is lost, and replaced with repeated boluses of fluids, usually crystalloids which were studiously avoided only a few hours before. Lactate levels, which normalised during

\section{Springer}




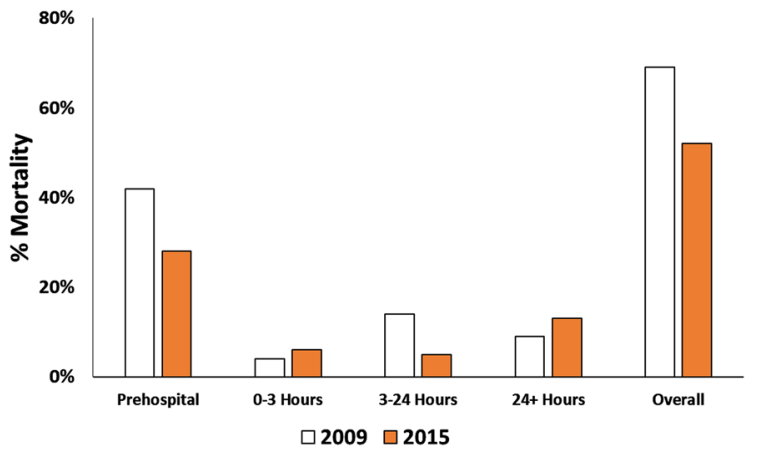

Fig. 1 Time distribution of mortality of patients activating a major haemorrhage protocol and receiving at least one unit of red blood cell transfusion. Overall mortality reduced 25\% from 2009 to 2015. A drop in pre-hospital mortality resulted in a 50\% higher death rate immediately post admission. Improvements in management of coagulopathy dramatically reduced mortality rates between $3 \mathrm{~h}$ and $24 \mathrm{~h}$ but was associated with a $44 \%$ increase in later deaths. Data extrapolated from London pre-hospital and in-hospital data [1, 3]; similar injury severity and admission characteristics across time cohorts

surgery, begin to rise, as does creatine kinase. Extremities become mottled. The patient eventually becomes unresponsive to escalating cardiac support, and active support is withdrawn. In some cases, severe cerebral swelling, even without traumatic brain injury, leads to cerebellar coning and brain death. This emerging pattern of cardiac and vascular failure often goes unrecognised early in the context of a patient with 'ongoing resuscitation requirements.

We have little understanding of why this fulminant cardiac and vascular failure occurs and how to prevent it. A secondary myocardial injury has been recognised in trauma patients, with elevated markers of cardiomyocyte damage on admission related to subsequent outcomes, including adverse cardiac events and mortality [8,9]. However the current picture is based on small studies, with little human experimental mechanistic investigation [9]. The degree to which it mirrors the cardiac dysfunction seen in sepsis is unknown [10]. For now, treatment of the failing heart is to make it work harder, and that of vascular failure is to give clear fluids. Neither is beneficial nor do they directly treat the problem, and currently there are no good alternatives. In the future, early administration of cardiac and vascular protective agents may be possible [10-12], or direct cardiac support through extracorporeal membrane oxygenation [13]. There may also be opportunities to combine cardiac support and ischaemic protection, through technologies such as selective aortic arch perfusion or emergency preservation resuscitation with deep hypothermia [14]. All would need to be delivered before significant myocardial loss has occurred, and therefore hyperacute identification and stratification of these patients will be vital.

The second group is later deaths associated with a prolonged indolent form of multiple organ failure, immunosuppression and multiple episodes of sepsis, referred to as persistent inflammation, immunosuppression and catabolism syndrome (PIICS) [15]. These patients consume large amounts of critical care and hospital resources before ultimately succumbing. PIICS may be a contemporary form of multiple organ dysfunction syndrome that occurs following an excessive or dysfunctional immune response to trauma. Human experimental research is needed to better understand the hyperacute immune response to damage before early stratification, identification of potential targets, and therapeutic modulation are possible.

In the evolution of the treatment of trauma-associated haemorrhage it is apparent that new management paradigms bring to the ICU patients who have sustained greater injury loads, and who have more ischaemia, more inflammatory activation and more cell death. Trauma patients are still dying of multiple organ failure, but the patterns of organ failure have changed. To keep these patients alive, we need innovations that help to identify at-risk patients before they become unsalvageable, and to better manage prolonged ischaemia, cardiogenic shock, persistent multiple organ dysfunction and immunoparesis. Focus in these areas may herald a new era of trauma resuscitation and a future generation of new survivors.

\section{Author details \\ ${ }^{1}$ Queen Mary University of London, London, UK. ${ }^{2}$ Barts Health NHS Trust, London, UK. ${ }^{3}$ London Major Trauma System, London, UK. ${ }^{4}$ College of Health and Medicine, Australian National University, Canberra, ACT, Australia. ${ }^{5}$ Can- berra Health Services, Canberra, ACT, Australia. ${ }^{6}$ Center for Translational Injury Research and Department of Surgery, University of Texas McGovern Medical School, Houston, TX, USA.}

Compliance with ethical standards Please add:

\section{Conflicts of interest}

Karim Brohi is Chief Investigator on the TOP-ART and CRYOSTAT2 trials. Russell Gruen is Chief Investigator on the PATCH trial. John Holcomb is the Chief Medical Officer of Prytime Medical, a founder and on the Board of Directors of Decisio Health, a Co-inventor of the Junctional Emergency Tourniquet Tool, and an advisor to Terumo BCT and Arsenal Medical.

\section{Ethical approval}

An approval by an ethics committee was not applicable.

\section{Publisher's Note}

Springer Nature remains neutral with regard to jurisdictional claims in published maps and institutional affiliations.

Received: 2 January 2019 Accepted: 4 February 2019

Published online: 11 February 2019 


\section{References}

1. Rehn M, Weaver A, Brohi K, Eshelby S, Green L, Røislien J, Lockey DJ (2008) Effect of pre-hospital red blood cell transfusion on mortality and time of death in civilian trauma patients. Shock. https://doi.org/10.1097/ SHK.0000000000001166.

2. Sperry JL, Guyette FX, Brown JB, PAMPer Study Group et al (2018) Prehospital plasma during air medical transport in trauma patients at risk for hemorrhagic shock. N Engl J Med. 379:315-326

3. Brohi K, Eaglestone S (2017) Traumatic coagulopathy and massive transfusion: improving outcomes and saving blood. NIHR Journals Library, Southampton

4. Marsden M, Carden R, Navaratne L et al (2018) Outcomes following trauma laparotomy for hypotensive trauma patients: a UK military and civilian perspective. J Trauma Acute Care Surg 85:620-625

5. Harvin JA, Maxim T, Inaba K et al (2017) Mortality after emergent trauma laparotomy: a multicenter, retrospective study. J Trauma Acute Care Surg 83:464-468

6. Bardes JM, Inaba K, Schellenberg M, Grabo D et al (2018) The contemporary timing of trauma deaths. J Trauma Acute Care Surg 84:893-899

7. Baker CC, Oppenheimer L, Stephens B, Lewis FR, Trunkey DD (1980) Epidemiology of trauma deaths. Am J Surg 140:144-150

8. Naganathar S, De'Ath HD, Wall J, Brohi K (2015) Admission biomarkers of trauma-induced secondary cardiac injury predict adverse cardiac events and are associated with plasma catecholamine levels. J Trauma Acute Care Surg 79:71-77
9. Wilson NM, Wall J, Naganathar V, Brohi K, De'Ath HD (2017) Mechanisms involved in secondary cardiac dysfunction in animal models of trauma and hemorrhagic shock. Shock 48:401-410

10. Sordi R, Nandra KK, Chiazza F et al (2017) Artesunate protects against the organ injury and dysfunction induced by severe hemorrhage and resuscitation. Ann Surg 265:408-417

11. Haywood-Watson RJ, Holcomb JB, Gonzalez EA et al (2011) Modulation of syndecan-1 shedding after hemorrhagic shock and resuscitation. PLoS One 6:e23530

12. Tian S, Lei I, Gao W, Liu L, Guo Y, Creech J et al (2018) HDAC inhibitor valproic acid protects heart function through Foxm 1 pathway after acute myocardial infarction. EBioMedicine S2352-3964(18):30574-30577

13. Strumwasser A, Tobin JM, Henry R et al (2018) Extracorporeal membrane oxygenation in trauma: a single institution experience and review of the literature. Int J Artif Organs 41:845-853

14. Moffatt SE, Mitchell SJB, Walke JL (2018) Deep and profound hypothermia in haemorrhagic shock, friend or foe? A systematic review. J R Army Med Corps 164:191-196

15. Mira JC, Brakenridge SC, Moldawer LL, Moore FA (2017) Persistent inflammation, immunosuppression and catabolism syndrome. Crit Care Clin $33: 245-258$ 